\title{
reviews
}

\section{Competition and community}

David C. Culver

Ecology and Evolution of Communities. Edited by Martin L. Cody and Jared M. Diamond. Pp. xii +545 (Belknap for Harvard University: Cambridge, Massachusetts and London, 1975). $\$ 17.70$.

THIS collection of 18 papers which grew out of a memorial symposium by former students and associates of the late Robert MacArthur contains a brief summary of his work and a bibliography of his papers. Continuing in the MacArthur tradition, the contributors look for and explain the broad patterns of community organisation, of ten at the expense of detail. A major theme running throughout is the impact of competition on community structure.

In the longest paper of the symposium Jared Diamond explains alternate stable communities of birds on islands near New Guinea by combining information about dispersal and competitive ability. Martin Cody investigates the diversity patterns of bird communities in Mediterranean climates and Henry Hespenheide assesses the importance of diet overlap in birds to species-packing problems. Using canonical correlation, James Karr and Frances James break new ground in identifying morphological and ecological correlates of bird communities. The negative correlation of bird species numbers with environmental variability suggests to John W. MacArthur that variability reflects the environmental resistance to invasion of new species. Taken together these studies provide strong support for the contention that competition is the major organising force in bird communities.

In papers dealing with non-avian communities-lizards (Eric Pianka), rodents (James Brown), butterflies (Arthur Shapiro) and diatoms (Ruth Patrick)-MacArthur's theories of species diversity seem less successful in explaining community structure. None of these papers directly confronts the basic premise that competition is the major kind of interspecific interaction. In general, predicted correlations match with the data but there are occasional bothersome discrepancies that either resist explanation or require elaborate qualifications to the theory. The pre-eminence of competition is challenged by Joseph Connell in a very provocative essay in which he argues that predation is much more important, except in harsh physical conditions. Connell proposes that experimental manipulations of communities yield more information than comparison of unperturbed communities. In another paper in this volume, Richard Levins shows, however, that the unexpected effects resulting from perturbations of complex communities can be difficult to interpret.

There are also several major theoretical contributions. Michael Rosenzweig develops several models which predict an asymptote to species diversity on continents. Henry Horn proposes a model of forest succession as a Markovian process which he partially tests with data from the Princeton woods. $\mathrm{He}$ also manages to include a few enjoyable barbs at critics of this kind of general approach to succession. William Schaffer and Madhav Gadgil develop models to explain life history strategies for plants, and Leigh develops some models to relate population fluctuations and species diversity. Robert May presents a major synthesis of the theoretical underpinnings of species abundance relations, and distinguishes the biological from the mathematical properties of such distributions. His work should facilitate the testing of hypotheses in this area. In a difficult but very important paper, Levins outlines loop analysis, a tech- nique enabling the analysis of communities where the direction but not the magnitude of the effect of one species on another is known. He uses loop diagrams to predict some unexpected consequences (such as a species selecting itself to extinction) of evolution in complex communities. The two concluding papers look aheadG. Evelyn Hutchinson reviews the relationship between theory and data in several areas of ecology, and Edward O. Wilson and Edwin Willis point out some possible applications of MacArthurian theory to the preservation of diversity in natural areas.

In general the symposium participants share a common view of ecology -one with an emphasis on rather imprecise models that predict overall patterns. In this volume the major weakness emerging from this approach lies in the too often sporadic and incomplete statistical testing of theory. That some authors seemed too committed to competition theory when consider alternative hypotheses led to its occasional reification. With the exception of the contributions of Levins and Hutchinson, there was no clear sense of the direction in which ecological theory should develop. This volume is a good summary, however, of the status of that part of ecology strongly influenced by MacArthur and his associates.

David Culver is Assistant Professor of Biology at Northwestern University, Evanston, Illinois.

\section{Monumental work revised}

The History of the British Flora: A Factual Basis for Phytogeography. Second Edition. By Sir Harry Godwin. Pp. $x+541+12$ plates. (Cambridge University: Cambridge and London, 1975.) $£ 30 ; \$ 85$.

THE publication of the second edition of Sir Harry Godwin's History of the British Flora has been an eagerly anticipated event in palaeoecological circles. There are few books which have had such a profound influence on the development of any branch of science than the first edition of this book. The volume of additional information which has accumulated since its publication in 1956 is, in large measure, a singular monument to its success. As a stand of reeds accumulates new material around itself, ultimately resulting in its own replacement, so has Godwin's work provided a basis for the research of many students, thereby encouraging the accretion of new records and findings. The appearance of a second edition of this book can therefore be regarded as the inevitable outcome of an autogenic process. 